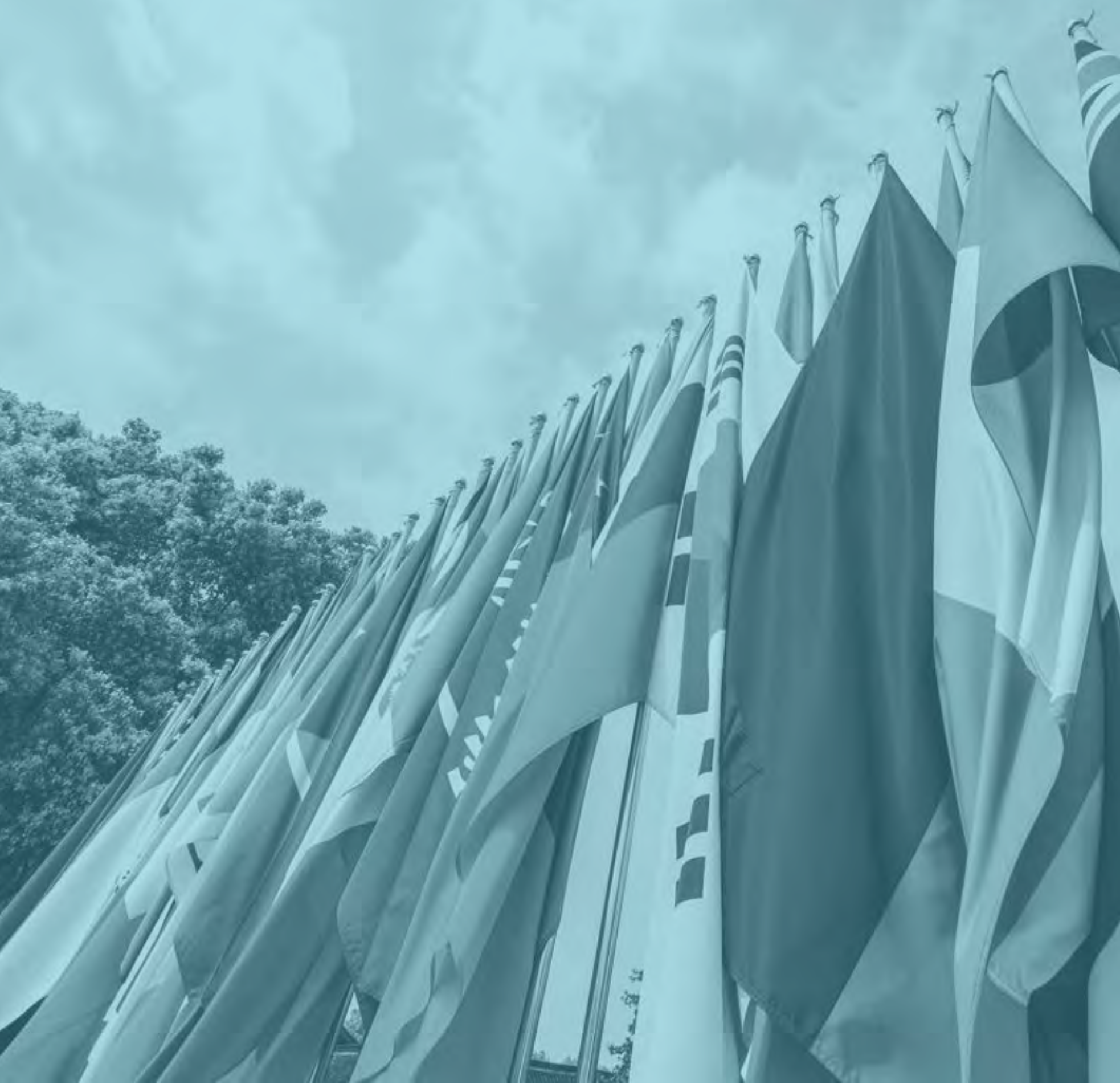

-10 


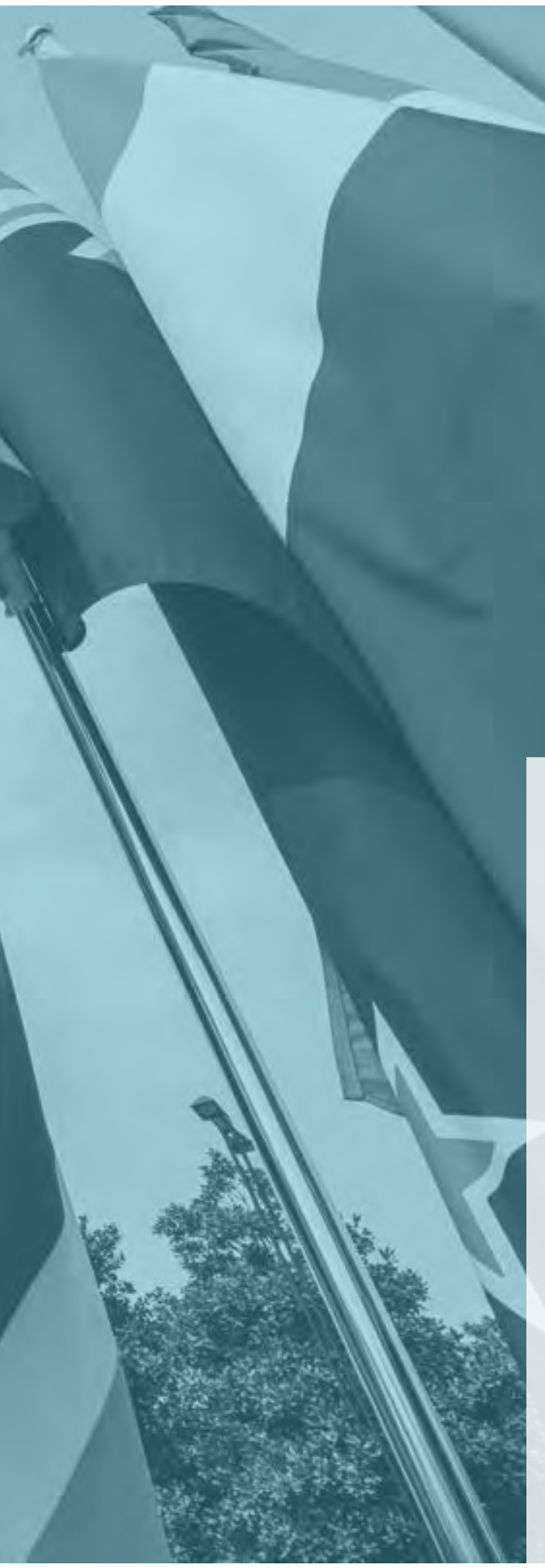

\section{Fomentando la igualdad de derechos en las constituciones: 193 países en perspectiva}

Aleta Sprague, Pam Stek, Amy Raub y Jody Heymann

DOI: 10.53110/PZUX2082

A. Introducción: Además de las lecciones por aprender de su propia historia constitucional, Chile puede obtener ideas para su proceso de reforma constitucional observando las tendencias en anteproyectos de constitución a nivel mundial. Este ensayo presenta datos globales de enfoques constitucionales sobre la igualdad de derechos para ofrecer contexto a los ciudadanos, autoridades responsables y la sociedad civil organizada en Chile, quienes darán forma a la nueva Constitución. En particular, señala por qué los derechos integrales importan, además de la experiencia y lecciones de otros países; examina las tendencias en protecciones constitucionales de los últimos 500 años y comparte apreciaciones de los datos globales sobre el impacto de las disposiciones de igualdad en áreas clave. Ya que los chilenos se disponen a tomar decisiones que moldearán el futuro de su propio país, esperamos que esta contribución ofrezca información útil sobre el alcance e implicaciones de los diferentes enfoques constitucionales sobre la igualdad de derechos a nivel mundial.

Aleta Sprague, Dra. en Jurisprudencia, es Analista jurídico en el WORLD Policy Analysis Center (WORLD' en la Universidad de California, Los Ángeles. Pam Stek. PhD, es historiadora en WORLD. Amy Raub. MS, es Analista Principal de Investigación en WORLD. Jody Heymann, MD, PhD, Profesora Distinguida en Fielding School of Public Health. Luskin School of Public Affairs. Geffen School of Medicine, Universidad de California, Los Ángeles y Directora fundadora de WORLD. 
B. El movimiento de los derechos humanos de los últimos sesenta años a nivel mundial ha conseguido mejoras para la igualdad, sin embargo, la persistente discriminación histórica continúa situando a ciertos colectivos en un elevado riesgo de pobreza, desventaja educacional, marginación política y mediante derechos constitucionales: Consideraciones importantes

violencia. Una base constitucional enfocada en el progreso y que aborde la igualdad de derechos exhaustivamente, incluirá prohibiciones de toda forma de discriminación y la flexibilidad para alcanzar las formas de discriminación emergentes y desconocidas, además, garantizar derechos sociales y económicos fundamentales para la igualdad de oportunidades y derechos políticos que permita dar voz a la sociedad.

C.

¿Los derechos de quién?

Abarcando todas lasformas de discriminación"

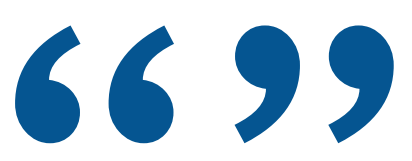

Una constitución hecha para proteger los derechos humanos universales prohibirá explícitamente todas las formas de discriminación, garantizando igualdad de derechos por razón de sexo, género, orientación sexual, identidad de género, raza, etnicidad, idioma, nivel socioeconómico, discapacidad, estatus migratorio y religión.

\section{Sexo y género}

Mujeres y niñas de todo el mundo siguen enfrentando barreras importantes para ejercer sus derechos fundamentales. Por ejemplo, en 2018, tres cuartas partes de la población mundial de niños estaba constituida por niñas sin oportunidad educativa. ${ }^{2}$ El salario de las mujeres es inferior al de los hombres en casi todo el mundo y existen persistentes brechas de género que fomentan la sobrerrepresentación de la mujer en trabajos mal pagados y la infrarrepresentación en puestos directivos. ${ }^{3}$ Igualmente, la mujer forma sólo una cuarta parte de la representación en los parlamentos de 153 países encuestados por el Foro Económico Mundial. ${ }^{4}$ La Organización Mundial de la Salud identifica la violencia de género como un problema de salud impor-

\footnotetext{
UNESCO, 2020, p. 9.

World Economic Forum, 2019, pp. 11 y 17; Organización Internacional del Trabajo, 2018, pp. 68-69.

4 Ibíd., World Economic Forum, 2019, p. 10.
} 
tante a nivel mundial, el que afecta transversalmente a las mujeres a través de países y grupos de ingreso. ${ }^{5}$ Mientras tanto, las normas de género restrictivas socavan el compromiso del hombre en el cuidado y crea barreras para las personas que persiguen su propio camino. Tanto la Convención sobre la Eliminación de Todas las Formas de Discriminación Contra la Mujer, aprobada por Chile y otros 188 países, y los Objetivos de Desarrollo Sostenible, adoptados por la Asamblea General de la ONU en 2015, comprometen a los gobiernos a garantizar la igualdad de género. Abordar la discriminación por razón de sexo y género es fundamental para garantizar la igualdad de derechos.

\section{Orientación sexual, características sexuales e identidad y expresión de género}

La discriminación legal contra las minorías sexuales y de género sigue siendo devastadoramente común: 68 países criminalizan la actividad sexual consentida entre dos adultos del mismo sexo, con penas como el encarcelamiento prolongado o la muerte. ${ }^{6}$ Ya que no existen tratados que protejan a estos colectivos, la orientación oficial de la ONU ha afirmado que la igualdad de derechos se aplica completamente a la población LGBT+. De la misma manera, órganos regionales como la Organización de los Estados Americanos, han emitido resoluciones similares. De hecho, fue un caso chileno -Atala Riffo y niñas vs. Chile- el que impulsó a la Corte Interamericana de Derechos Humanos a confirmar que la Convención Americana de Derechos Humanos prohíbe la discriminación por razón de orientación sexual. Dada la persistencia de la discriminación por orientación sexual e identidad de género y el creciente consenso sobre la necesidad de protecciones legales explícitas, garantizar la igualdad de derechos sobre las bases de la orientación sexual y la identidad de género apoyaría poderosamente la capacidad de la Constitución para proteger completamente la igualdad.

\section{Raza, etnia e idioma}

La discriminación por razón de raza y etnia continúa socavando oportunidades a nivel mundial. En muchos países, niños y niñas de minorías étnicas tienen menor posibilidad de completar la educación secundaria, como también niños y niñas pertenecientes a minorías lingüísticas -más del $40 \%$ de la población mundial - tienen dificultad para estudiar en su propio idioma. ${ }^{7}$ Los pueblos indígenas y otros grupos étnicos marginados siguen teniendo

World Health Organization, 2013, p. 2.

ILGA World, 2019, p. 47.

United Nations (2016) p. 59. 
empleos poco cualificados, mal pagados y sin seguridad social. ${ }^{8}$ Estos grupos también sufren mayor riesgo de violencia en sus relaciones con instituciones del Estado, lugares de trabajo, escuelas y lugares públicos. En este contexto, las constituciones son instrumentos especialmente importantes para prohibir la discriminación por razón de género, etnicidad e idioma. Además, Chile y otros 181 países han aprobado la Convención Internacional sobre la Eliminación de todas las Formas de Discriminación Racial, la que condena todo tipo de discriminación racial en todos los aspectos de la vida pública.

\section{Nivel socioeconómico}

La discriminación por razones socioeconómicas continúa siendo un lugar común. Por ejemplo, estudios demuestran que los empleadores discriminan en las contrataciones sobre las bases de acentos regionales, códigos postales, apariencia de la dentadura y otros indicadores de clase social. ${ }^{9}$ Además, en el contexto de la creciente privatización de bienes públicos, las barreras económicas limitan el acceso a la educación, atención médica e incluso la posibilidad de participar en procesos políticos, comprometiendo derechos universalmente protegidos. Abordar tanto la discriminación por estatus socioeconómico como las barreras financieras discriminatorias fortalecería la capacidad de la Constitución de proporcionar cimientos para la igualdad de oportunidades.

\section{Personas con discapacidad}

Cerca de mil millones de niños y adultos a nivel mundial forman parte de este colectivo, el cual enfrenta discriminación explícita en el empleo y la educación, además de sufrir las tasas más altas de prejuicios implícitos. La discriminación de las personas con discapacidad también afecta la política: estudios demuestran que la inaccesibilidad a los centros de votación reduce la participación de este colectivo. ${ }^{10}$ La Convención sobre los Derechos de las Personas con Discapacidad, con 182 países miembros incluyendo Chile, es uno de los tratados de derechos humanos más rápidamente aprobados en la historia y garantiza integralmente la igualdad de derechos, la total participación del colectivo y aporta las bases para la toma de decisiones en los tribunales y las reformas constitucionales a nivel mundial. Una constitución que garantice la igualdad de derechos de las personas con discapacidad construiría sobre dicho progreso y sentaría las bases para una sociedad inclusiva.

8 Organización Internacional del Trabajo, 2020, p. 68.

9 Siddique, 2011; Bertrand y Mullainathan, 2004, p. 992; Moeller, et al., 2015, p. 26.

10 Schury Adya, 2013, pp. 836-837,. 


\section{Estatus migratorio}

En el 2020, los inmigrantes y refugiados formaban 272 millones de personas a nivel mundial. Los migrantes suelen sufrir discriminación que se intersecta con su etnia, nacionalidad y/o religión, junto a las restricciones en el acceso a asistencia médica básica, escuelas para sus hijos y condiciones seguras y justas de trabajo. Acuerdos globales protegen estos derechos: la Convención sobre el Estatuto de los Refugiados y la Convención internacional sobre la protección de los derechos de todos los trabajadores migratorios y de sus familiares -aprobadas por Chile-garantizan el derecho a la educación para todos los niños y niñas independientemente de su estatus migratorio; ${ }^{11}$ prohíben la discriminación; ${ }^{12}$ e incluyen protecciones para las condiciones laborales independientemente de la ciudadanía. ${ }^{13}$ Los tratados internacionales también protegen el derecho a la salud para todos. ${ }^{14}$ Además, cuando se violan los derechos de los migrantes las consecuencias también afectan a los ciudadanos: negar asistencia médica a los migrantes puede incrementar la propagación de enfermedades infecciosas, así como, tolerar condiciones laborales injustas puede socavar los estándares laborales para todos. Dado el incremento a gran escala de las migraciones forzadas y hechas posibles durante el último siglo, abordar constitucionalmente los derechos de las personas no ciudadanas tendría importantes impactos normativos y prácticos.

\section{Religión}

Transversalmente en los países, la discriminación sobre la base de una identidad religiosa real o presunta, junto a la opresión religiosa realizada por los gobiernos, es responsable por la marginalización, acoso y abuso de los derechos humanos de millones de personas. Un estudio del 2018 demuestra que 53 países reportan niveles altos o muy altos de hostilidad social relacionados con la religión. ${ }^{15}$ Junto con la Declaración Universal de los Derechos

11 Convención sobre el Estatuto de los Refugiados, 1951, art. 22; Convención internacional sobre la protección de los derechos de todos los trabajadores migratorios y de sus familiares, 1990, arts. 30 y 45.

12 Ibíd., Convención sobre el Estatuto de los Refugiados, art. 3; Convención internacional sobre la protección de los derechos de todos los trabajadores migratorios y de sus familiares, art. 7.

13 Ibíd., Convención sobre el Estatuto de los Refugiados, arts. 17 y 24; Convención internacional sobre la protección de los derechos de todos los trabajadores migratorios y de sus familiares, art. 25.

14 Ibíd., Convención internacional sobre la protección de los derechos de todos los trabajadores migratorios y de sus familiares, arts. 28, 43 y 45; Declaración Universal de Derechos Humanos, art. 25; Pacto Internacional de Derechos Económicos, Sociales y Culturales, 1996, art. 12.

15 Majumdar y Villa, 2020, pp. 5-12. 
Humanos, el Pacto Internacional de Derechos Civiles y Políticos - aprobado por Chile y otros 172 países- prohíbe la discriminación por motivos de religión o credo. Si bien proteger derechos igualitarios independientemente de la religión no justifica las prácticas religiosas que amenazan los derechos de otras personas, prohibir constitucionalmente la discriminación basada en la religión, credo o la ausencia de credo, profundizaría principios democráticos fundamentales.

D.

¿́Cuáles
derechos?:
Protecciones
importantes para
todos los colectivos
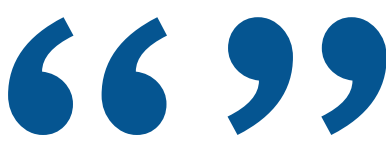

Una constitución diseñada para proteger los derechos humanos universales, debería como mínimo prohibir integralmente la discriminación directa e indirecta, garantizar los derechos civiles y políticos fundamentales y consagrar los derechos sociales y económicos, como la salud, educación, condiciones laborales dignas y apoyo económico.

\section{Disposiciones generales de no discriminación e igualdad de derechos}

Una constitución diseñada para proteger los derechos humanos universales dispondrá una garantía de igualdad comprensiva, prohibiendo la discriminación en todas las formas discutidas anteriormente. Ejemplos de muchos países demuestran por qué las protecciones constitucionales específicas importan. Por ejemplo, en México, las protecciones contra la discriminación por razón de discapacidad lograron a una resolución histórica contra una cadena de hoteles que prohibía a este colectivo postular a sus ofertas de trabajo; ${ }^{16}$ en Sudáfrica, las garantías constitucionales de igualdad de derechos independientemente de la orientación sexual impulsaron la reforma de una ley de inmigración que excluía parejas del mismo sexo. ${ }^{17}$ Entretanto, aunque las disposiciones generales sobre igualdad que no enumeran los tipos de discriminación prohibida han tenido un gran impacto, su cobertura es menos predecible y consistente, a la vez que carece del valor normativo de un mandato claro e inequívoco sobre la igualdad de derechos de un colectivo.

Corte Suprema de México, rol 1387/2012, Amparo Directo en Revisión. National Coalition for Gay and Lesbian Equality and Others vs. Minister of Home Affairs and Others, 1999. 


\section{Abordando la discriminación indirecta}

Para fortalecer las prohibiciones de discriminación, una constitución diseñada para promover la igualdad también prohibiría la discriminación indirecta - políticas o prácticas de apariencia neutral pero que perjudican desproporcionadamente a ciertas poblaciones. Por ejemplo, restringir la elegibilidad para un trabajo basándose en un mínimo de altura, si bien no discrimina explícitamente a las mujeres, en efecto excluirá desproporcionadamente a candidatas mujeres. Algunos casos de discriminación indirecta o de "impacto desigual" pueden ser inintencionados o el resultado de prejuicios implícitos en vez de explícitos; otros, sin embargo, están claramente destinados a elegir como blanco un grupo en particular, eludiendo las protecciones contra la discriminación directa. Un ejemplo de esto es el uso de pruebas de alfabetización como requisito para votar en el sur de EE.UU a principios del siglo XX, el que no prohibía explícitamente el voto sobre la base de la raza, pero claramente estaba dirigido a privar de sus derechos civiles a afroamericanos a quienes les había sido negada una educación formal. Las disposiciones constitucionales que prohíben explícitamente la discriminación indirecta han tenido impactos, incluyendo la invalidación de pruebas sesgadas de acceso al empleo en el Reino Unido y la aseguración de compensaciones equitativas a víctimas de accidentes del transporte público en Sudáfrica. En contraste, sin protecciones claras contra impactos desiguales, los tribunales han validado grandes injusticias, tales como desigualdades raciales en las sentencias de pena de muerte en EE.UU. ${ }^{18}$

\section{Protecciones para los derechos civiles, políticos, sociales y económicos}

Las protecciones para los derechos civiles y políticos son fundamentales para asegurar que todos puedan participar en la vida pública y privada e influenciar las decisiones de sus gobiernos. Los derechos civiles fundamentales incluyen, entre otras cosas, la libertad de expresión, de asociación y credo; el derecho a la libertad y al debido proceso; la libertad de tránsito y el derecho a votar libre de discriminación o coacción. Igualmente, los derechos sociales y económicos son críticos para crear sociedades justas e inclusivas en las que todos puedan satisfacer sus necesidades fundamentales. Mientras las constituciones contemporáneas reconocen una variedad de derechos sociales y económicos, garantías universales de educación, salud pública y asistencia sanitaria, empleo decente y seguridad de ingresos, son bases particularmente poderosas para avanzar la igualdad para todos. ${ }^{19}$

\footnotetext{
18 Essop vs. Home Office, 2017; Mvumvu and Others vs. Minister of Transport and Another, 2011; McKleskey vs. Kemp, 1987.

19 Para más detalles sobre el enfoque de los países para estos derechos y su prevalencia global, ver Heymann, Sprague y Raub, 2020; y Sprague, Raub y Heymann, 2020.
} 
E. En esta sección presentamos datos que capturan los detalles de enfoques constitucionales para derechos igualitarios a través de todos los 193 Estados que eran miembros de la ONU en 2017, y analizamos sus progresos y brechas.

del mundo:

Protecciones para derechos igualitarios en 193

Constituciones

\section{Igualdad de derechos y no discriminación}

- Sexo y género

Los últimos cincuenta años han presenciado una dramática transformación de las garantías constitucionales para la igualdad de derechos sobre la base del sexo. Todas las constituciones escritas desde el año 2000 han abordado la igualdad de los sexos y/o el género, en comparación con sólo la mitad de aquellas aprobadas antes de 1970 . En conjunto, el 85\% de las constituciones a nivel mundial garantizan la igualdad de derechos o prohíben la discriminación por razón de sexo y/o género.

\section{9}

Además del sexo y género, abordar el embarazo, el estatus matrimonial y familiar proveerá una base más sólida para el fomento de la igualdad de género.

Muchas menos prohíben la discriminación por prestación de cuidados, lo que afecta desproporcionadamente a las mujeres pero tiene consecuencias para los trabajadores de todos los géneros. Por ejemplo, mientras las mujeres casadas y las madres sufren discriminación en la contratación y promoción debido a la percepción de su estatus de cuidadoras, los empleadores también discriminan comúnmente a los hombres que desafían los estereotipos de género al priorizar sus responsabilidades de cuidado.

Para cerrar esa brecha, algunas constituciones han comenzado a abordar explícitamente la discriminación por razón de estatus matrimonial, familiar y embarazo -un importante avance a la luz de sentencias judiciales que señalan que las protecciones contra la discriminación de sexo no necesariamente incluyen la discriminación por estos motivos relacionados. ${ }^{20}$ Actualmente, el $6 \%$ de las constituciones prohíben explícitamente la discriminación por embarazo y un $8 \%$ prohíbe la discriminación por razón de estatus matrimonial.

20 Ver, por ejemplo, Geduldig vs. Aiello, 1974; Nussbaum, 2001, p. 49. 
En contraste con la discriminación por sexo, algunos países prohíben constitucionalmente la discriminación por razón de orientación sexual o de identidad de género. Desde 1996, cuando la Constitución Sudafricana se convirtió en la primera en proteger explícitamente los derechos igualitarios independientemente de la orientación sexual, 11 países más han seguido el ejemplo. Recientemente, la Constitución de Cuba de 2019 prohibió la discriminación tanto por razón de orientación sexual como por identidad de género, sumándose a otros 6 países a nivel mundial con protecciones por ambos motivos.

Aunque pocas constituciones contienen protecciones OSIG, millones de personas LGBT+ alrededor del mundo han conseguido derechos mediante sentencias judiciales basadas en otras garantías constitucionales..$^{21}$ Aunque son victorias

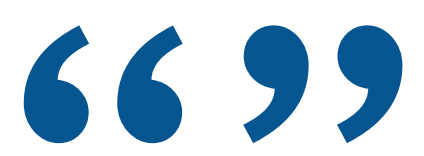

A pesar de que los tribunales han fomentado los derechos para este colectivo mediante una gama de disposiciones constitucionales, no hay nada que sustituya una garantía explícita de igualdad de derechos, especialmente, dada la demostrada amenaza de enmiendas constitucionales discriminatorias. importantes, estas decisiones también demuestran que, frente a la ausencia de un lenguaje constitucional claro, los tribunales han sido garantes impredecibles y poco fiables de la igualdad de derechos OSIG. Adicionalmente, establecer derechos en un lenguaje claro es importante para la protección contra enmiendas constitucionales restrictivas de derechos: desde el año 2000, doce países han adoptado un lenguaje constitucional que prohíbe o permite legislación para prohibir el matrimonio entre personas del mismo sexo, ilustrando la reacción que a menudo sigue a los avances en materia de igualdad.

\section{- Raza, etnicidad e idioma}

La mayoría de los países (76\%) establecen garantías constitucionales basadas en la raza y/o etnia, mientras el 44\% prohíbe la discriminación idiomática, que normalmente se asocia con la discriminación étnica. Estas protecciones son más comunes en las nuevas constituciones: sólo el $49 \%$ de las constituciones adoptadas antes de 1970 abordan la igualdad de derechos en base a la raza y/o etnia, en comparación con al menos el 73\% de las adoptadas cada década después.

21 Ver, por ejemplo, Op. Cit., Heymann, Sprague y Raub, 2020, pp. 139- 142. 


\section{9}

Aunque las protecciones constitucionales sobre la base de la raza y la etnia son vitales por sí solas, la discriminación racial y étnica usualmente se intersecta con discriminaciones por otros motivos, ilustrando que tanto las constituciones como los tribunales pueden fortalecer las protecciones tomando un enfoque comprensivo e interseccional para garantizar la igualdad de derechos.
La discriminación suele atravesar diferentes aspectos de la identidad, sin embargo, la ley normalmente define cada tipo de discriminación separadamente y las cortes evalúan cada demanda consecutivamente. La discriminación interseccional se refiere a las formas distintas y compuestas de discriminación, vulnerabilidad y subordinación, que resultan de la superposición de diferentes tipos de discriminación. ${ }^{22}$ A pesar de que un número creciente de países ha comenzado a abordar legislativamente la interseccionalidad y otros conceptos relacionados como la discriminación múltiple, las disposiciones constitucionales comparables siguen siendo raras. ${ }^{23} \mathrm{Si}$ bien la discriminación interseccional afecta personas de todos los grupos marginalizados, la discriminación basada en la raza o la etnia es especialmente probable de ser de naturaleza interseccional, dada la discriminación histórica entre países que ha resultado en disparidades raciales y étnicas, que suelen alinearse cercanamente con disparidades socioeconómicas: la segregación del mercado laboral por raza, etnia y género; y la relación entre raza, etnia y estatus migratorio.

Avanzando hacia el futuro, consagrar el reconocimiento de la interseccionalidad en las constituciones - o como mínimo asegurar que éstas establezcan coberturas y flexibilidades adecuadas para alcanzar formas interseccionales de discriminación- fortalecerá la capacidad de las constituciones para ofrecer protecciones suficientes.

\section{- Nivel socioeconómico}

Más de la mitad de las constituciones en el mundo (59\%) contienen disposiciones que prohíben las formas de discriminación por estatus socioeconómico. Los 90's fueron la primera década en que una mayoría de nuevas constituciones (83\%) incluyeron disposiciones que prohibían este tipo de discriminación. En los 2000, esta cifra bajó al 63\%, pero rebotó al 83\% en el período desde el 2010-2017.

La discriminación por estatus socioeconómico persiste no sólo en la forma de prejuicios explícitos en el trabajo, escuelas y espacios públicos, sino también mediante barreras financieras frente a recursos claves como la salud y la educación. Condicionar el acceso a los servicios médicos y sanitarios por la capacidad de pago amplía las disparidades socioeconómicas, desalentando a las personas de bajos recursos de buscar cuidados y aumentando los riesgos de enfermedades y muertes previsibles. Asimismo, cobrar matrículas en la

22 Mahlangu and Another vs. Minister of Labour and Others, 2020.

23 Fredman, 2016, pp. 51-53. 
educación pública lleva a la exclusión desproporcionada de niñas, niños con discapacidad y estudiantes provenientes de familias con bajos ingresos.

Una porción significativa de constituciones abordan las barreras de ingresos directamente, con impactos comprobados en el acceso y la inclusión. ${ }^{24}$ El 53\% de las constituciones garantizan el derecho a la educación primaria gratuita, y el $30 \%$ hacen lo propio con la educación secundaria. El 10\% garantiza la atención médica gratuita universal, mientras otro $6 \%$ garantiza el derecho de niños y adultos de escasos recursos a la atención médica. ${ }^{25}$ Juntas, las prohibiciones constituciones de la discriminación por estatus socioeconómico y la remoción de barreras financieras de los derechos fundamentales pueden profundizar la igualdad en la práctica.

\section{9}

Además de las protecciones específicas contra la discriminación por estatus socioeconómico, disposiciones constitucionales que remueven barreras financieras para el disfrute de derechos fundamentales -incluyendo salud, educación y voto-pueden apoyar poderosamente su realización universal.

\section{- Personas con discapacidad}

Globalmente, solo $27 \%$ de las constituciones garantizan la igualdad de derechos independientemente de la discapacidad. Sin embargo, el tratamiento de la discapacidad se está convirtiendo cada vez más en una norma constitucional: en los 90's, sólo el $27 \%$ de las nuevas constituciones abordaban la igualdad de derechos sobre la base de la discapacidad, comparado con el $47 \%$ en la década del 2000 y el $71 \%$ entre el 2010-2017.

\section{9}

Para asegurar la igualdad de derechos independientemente de la discapacidad, la sola prohibición de la discriminación es raramente suficiente -garantizar ajustes razonables en el trabajo y educación inclusiva proveerá una base constitucional más fuerte para la igualdad.

Prohibir la discriminación por razón de discapacidad es un primer paso fundamental. Sin embargo, la igualdad de derechos se mantendrá incompleta si las personas con discapacidad carecen de acceso igualitario a escuelas, lugares de trabajo, información, transporte y espacios públicos, y procesos políticos. Por ejemplo, una escuela con escaleras, pero sin rampa o ascensor excluirá a la entrada de usuarios de sillas de ruedas; un lugar de trabajo que

\footnotetext{
24 Ver, por ejemplo, Op. Cit., Heymann, Sprague y Raub, 2020, pp. 190-191.

25 Para más información sobre los derechos de la salud y la educación, visite https://www.worldpolicycenter.org/topics/constitutions/policies.
} 
no ofrece lectores de pantalla imposibilitará a los empleados ciegos de hacer su trabajo. Consecuentemente, junto a la no discriminación, las garantías legales de ajustes razonables y educación inclusiva son centrales para la igualdad de derechos de las personas con discapacidad. Más aún, la evidencia demuestra que todos los estudiantes aprenden bien en lugares inclusivos y que la mayoría de los ajustes razonables tienen amplios beneficios.

En décadas recientes, los países han conseguido un gran avance en el reforzamiento de leyes protectoras de la igualdad de derechos sobre la base de la discapacidad; sin embargo, significativas brechas se mantienen en las constituciones. De 193 constituciones, sólo dos explícitamente proveen ajustes razonables en el trabajo, siete abordan la educación inclusiva para niños con discapacidad, y ninguna incluye lenguaje que claramente mandate la inclusión total. Sin embargo, estas disposiciones han tenido impacto y pueden proveer un ejemplo para otros países que busquen consagrar derechos más fuertes. ${ }^{26}$

\section{- Estatus migratorio}

\section{9}

\section{Enmarcar los derechos consti-} tucionales sólo para los "ciudadanos" puede excluir a refugiados y migrantes de estas protecciones fundamentales y socavar los estándares para todos; en contraste, garantizar el acceso de los no ciudadanos a servicios médicos básicos, educación y condiciones seguras de trabajo, puede proveer una base poderosa para defender los derechos humanos universales.

El 22\% de las constituciones prohíben la discriminación por razón de ciudadanía, mientras que el $60 \%$ garantiza igualdad de derechos independientemente de la nacionalidad y el $8 \%$ prohíbe la discriminación contra los apátridas. Notablemente, sólo el $25 \%$ de las constituciones adoptadas desde el 2010 y el 16\% adoptadas en la década del 2000 incluyen garantías explícitas para la igualdad de derechos de los no ciudadanos, comparado con el $40 \%$ de las constituciones escritas en los '90s. Este cambio, aunque problemático, puede reflejar ante todo desarrollos geopolíticos. Después de la disolución de la Unión Soviética, casi todas las constituciones redactadas en los 90's protegían los derechos independientemente de la ciudadanía. Aunque las constituciones más recientes han sido menos propensas a incluir estas herramientas, la reciente escalada de xenofobia manifiesta en muchas naciones pone de relieve su continua importancia vital.

Las disposiciones de igualdad constitucional pueden ofrecer importantes apoyos para defender los derechos de los migrantes. Sin embargo, cuando las constituciones articulan derechos usando el lenguaje de "ciudadanía", los refugiados y migrantes pueden sufrir la exclusión incluso respecto de derechos fundamentales como la educación y la salud garantizada para todos en acuerdos globales. Defensores han llamado la atención sobre esta amenaza.

26 Ver, por ejemplo, Op. Cit., Heymann, Sprague y Raub, 2020, pp. 158-159. 
Más allá del lenguaje inclusivo, las garantías específicas de la igualdad de derechos para los no nacionales probablemente ofrecerán salvaguardias más sólidas para la igualdad de derechos, especialmente respecto a la educación, atención médica y empleo decente. Globalmente, el 14\% de las constituciones garantizan el derecho de los no ciudadanos a la salud, $17 \%$ garantizan su derecho a la educación y $21 \%$ protege algunos aspectos de la igualdad y la no discriminación en la vida laboral, ofreciendo bases importantes para defender estos derechos independientemente del estatus migratorio.

- Religión

$78 \%$ de las constituciones prohíben la discriminación sobre la base de la religión, incluyendo un 92\% de aquellas adoptadas entre el 2010 y 2017 . Sin embargo, muchas menos adoptan un enfoque comprensivo para asegurar la igualdad de todos independientemente de la religión, credo o carencia de éste.

Una constitución diseñada para apoyar la igualdad de derechos independientemente del credo asegurará que las personas puedan observar su fe al mismo tiempo que frenará las prácticas religiosas discriminatorias, y ordenará la completa neutralidad del Estado respecto de todas las religiones, credos y no credos. Los acuerdos internacionales reconocen estos principios: por ejemplo, el PIDCP protege la libertad de culto, prohíbe la discriminación religiosa y garantiza la libertad de credo sin calificaciones, pero llama a limitar la libertad de práctica para proteger los derechos de otros.

Junto al $78 \%$ de constituciones que prohíben la discriminación sobre la base de la religión, el 95\% protege la libertad de culto. El $41 \%$ establece el secularismo o la separación de la iglesia y el Estado, mientras la cuarta parte explícitamente garantiza la libertad de no creer, prácticar o manifestar la religión personal. Además, el $46 \%$ de las constituciones especifican que las prácticas religiosas pueden ser limitadas para proteger los derechos fundamentales 6699

Además de prohibir la discriminación religiosa, las constituciones pueden proteger más plenamente la igualdad de derechos transversalmente en todas las religiones, protegiendo la libertad de religión, de credo y no credo; garantizando la igualdad de derechos de todos sin excepción para leyes o prácticas religiosas; y evitando un lenguaje constitucional que priorice una religión o la religión en general. de otros. $^{27}$

Los países han usado varias estrategias para proteger la libertad de culto a la vez que protegen otros derechos. Garantías comprensivas de la igualdad de derechos en todos los contextos pueden ayudar a asegurar que los derechos religiosos no tengan prioridad sobre otros estatutos protegidos, como también lo pueden lograr disposiciones constitucionales que específica-

27 Pacto Internacional de Derechos Civiles y Políticos, 1966, art. 18; Comité de Derechos Humanos, 1993; Comité de Derechos Humanos, 2000. 
mente abordan conflictos entre prácticas religiosas y los derechos fundamentales de otros ${ }^{28}$ Otra estrategia para proteger los derechos de todos es hacer que la constitución sea la ley suprema del país, sin excepciones para las leyes religiosas o las costumbres; el $48 \%$ de las constituciones consideran las disposiciones constitucionales como supremas, mientras que otro $1 \%$ subordina específicamente las leyes religiosas a la constitución.

En resumen, más allá de prohibir la discriminación religiosa, los redactores de la constitución que aspiren a proteger comprensivamente la igualdad de derechos se beneficiarían del examen de cómo las referencias a la religión a través de todo el texto pueden influenciar los derechos de las personas de todas las creencias.

\section{Discriminación indirecta}

Si bien la discriminación indirecta es un concepto nuevo en el derecho de la igualdad, algunas constituciones recientemente reescritas ofrecen protecciones específicas contra la discriminación indirecta en sus disposiciones de igualdad de derechos. Específicamente, el $5 \%$ de las constituciones prohíben la discriminación indirecta de género y de raza o etnia, respectivamente. Aunque estas disposiciones se mantienen relativamente poco comunes, los recientes procesos de redacción constitucional han reconocido su importancia y las consecuencias de su omisión. Sudáfrica, por ejemplo, específicamente incluyó la discriminación indirecta en su Constitución de 1996 después de presenciar las consecuencias para la igualdad que sufrió EE.UU. falló al no reconocerla. ${ }^{29}$

\section{Formas de discriminación desconocidas, emergentes y transversales}

Mientras los tipos de discriminación descritos en este ensayo siguen siendo problemáticamente comunes en muchos países, no son en ningún caso exhaustivos. Más aún, nuevas formas de discriminación emergen a medida que las sociedades evolucionan. La discriminación genética, por ejemplo, es una nueva forma de discriminación hecha posible gracias a la tecnología moderna. Una forma en que las constituciones pueden alcanzar formas adicionales de discriminación más allá de las prohibidas específicamente, es a través de la inclusión de lenguaje como "o cualquier otra condición" en las provisiones antidiscriminación. A pesar de que no hay sustitutos para la enumeración comprensiva de los estatus protegidos, este lenguaje general puede proveer la flexibilidad para alcanzar formas de discriminación emergentes, poco reconocidas y transversales.

\footnotetext{
28 Ver, por ejemplo, Op. Cit., Heymann, Sprague y Raub, 2020, pp. 105.
}

29 Wing, 2008, p. 73. 


\section{Abordando la discriminación histórica: Consideraciones contexto- específicas}

\section{9}

Las disposiciones constitucionales que permiten la adopción de medidas afirmativas para profundizar la igualdad pueden ayudar a abordar las consecuencias de la discriminación, exclusión y presión pasada y continuas, que limitan las oportunidades actuales y el acceso a los recursos de grupos marginados.

A través de los países, diferentes grupos han enfrentado grados variables de discriminación y exclusión histórica, incluyendo mediante leyes que limitaron el acceso a la educación, el empleo y los recursos. Diseñar medidas afirmativas efectivas es una tarea contexto-específica que requiere la consideración de preguntas tales como: qué colectivos incluir, la duración ideal de la política, y cómo medir la eficacia de la política. Estas preguntas de diseño pueden ser complejas, pero medidas afirmativas bien elaboradas pueden ayudar a conseguir la promesa de la igualdad de derechos al mitigar los daños de injusticias pasadas y cambiar la representación y acceso a las instituciones.

A través de los países, las medidas afirmativas suelen ser controversiales y pueden enfrentar retos basados en las garantías constitucionales de la igualdad de derechos que estipulan ampliamente la igualdad ante la ley $\sin$ proveer pasos afirmativos para conseguir la igualdad en la práctica. Porque las medidas afirmativas usualmente son políticamente controvertidas, las disposiciones constitucionales que específicamente permiten su implementación ofrecen un fuerte cimiento para estas políticas y decisiones judiciales relacionadas. Las concesiones constitucionales expresas para las medidas afirmativas pueden proteger contra lecturas restringidas de la igualdad que mandaten el tratamiento idéntico en vez de equitativo en toda circunstancia. 
Las disposiciones constitucionales que tienen impacto en el avance de la igualdad en la práctica abarcan una amplia gama de derechos, incluyendo garantías detalladas de la igualdad de derechos y prohibiciones de discriminación directa e indirecta; garantías de derechos civiles, políticos, sociales y económicos; y enfoques más dirigidos al abordaje de barreras persistentes a la igualdad de derechos para grupos marginados.

En décadas recientes, las protecciones constitucionales se han vuelto más prevalentes en casi todas estas áreas, reflejando el éxito de los movimientos sociales nacionales y globales, así como la influencia de protecciones fuertes y más específicas en tratados de derechos humanos ampliamente aprobados. Más allá, áreas emergentes de la protección constitucional -incluyendo las garantías de igualdad sobre la base del estatus de cuidadores, derechos explícitos a los ajustes razonables y a la educación inclusiva, y protecciones explícitas contra la discriminación sobre la base de la orientación sexual e identidad de género- indican que la continua expansión es tanto probable como necesaria para garantizar la igualdad de derechos para todos.

Desde una perspectiva práctica, las garantías de igualdad de derechos constitucionales pueden y han facilitado el acceso a la educación, empleos y a la atención médica, y han proveído a las personas la libertad de llevar una vida autodirigida. Sin embargo, igualmente y quizás más importantes, son los impactos de las constituciones en las normas y valores compartidos, y el poder expresivo que tiene su lenguaje para ratificar la dignidad común, la humanidad y la igualdad de derechos de todos. 


\section{- BIBLIOGRAFIA}

Bertrand, M. y Mullainathan, S. (2004)

'Are Emily and Greg More Employable than Lakisha and Jamal? A Field Experiment on Labor Market Discrimination, The American Economic Review, 94(4):991- 1013. Disponible en: https://www.jstor.org/stable/3592802 (Consulta: 23 agosto 2021).

Comité de Derechos Humanos (1993)

Comentario general No 22 (48) (art. 18) 1/. Documento No. CCPR/C/21/Rev.1/ Add.4. Disponible en: https://tbinternet.ohchr.org/_layouts/15/treatybodyexternal/Download.aspx?symbolno=CCPR\%2fC\%2f21\%2fRev.1\%2fAdd.4\&Lan$g=e n$ (Consulta: 23 agosto 2021).

Comité de Derechos Humanos (2000)

Observación general $N^{\circ} 28$ La igualdad de derechos entre hombres y mujeres (artículo 3). Documento No. HRI/GEN/1/Rev.9 (Vol. I). disponible en: https:// tbinternet.ohchr.org/_layouts/15/treatybodyexternal/Download.aspx?symbolno=CCPR\%2fC\%2f21\%2fRev.1\%2fAdd.10\&Lang=en (Consulta: 23 agosto 2021).

Convención internacional sobre la protección de los derechos de todos los trabajadores migratorios y de sus familiares (1990)

Organización de Naciones Unidas. Disponible en: https://treaties.un.org/doc/ Treaties/1990/12/19901218\%2008-12\%20AM/Ch_IV_13p.pdf (Consulta: 23 agosto 2021).

Convención sobre el Estatuto de los Refugiados (1951)

Organización de Naciones Unidas. Disponible en: https://reaties.un.org/doc/ Treaties/1954/04/19540422\%2000-23\%20AM/Ch_V_2p.pdf (Consulta: 23 agosto 2021).

Corte Suprema de México (2012)

Rol 1387/2012. Amparo En Revisión. Disponible en: http://www2.scjn.gob.mx/ juridica/engroses/1/2012/10/2_139091_1794.doc (Consulta: 23 agosto 2021).

Declaración Universal de Derechos Humanos (1948)

Organización de Naciones Unidas. Disponible en: https://www.un.org/en/universal-declaration-human-rights/(Consulta: 23 agosto 2021).

Fredman, S. (2016)

Intersectional Discrimination in EU Gender Equality and Non-Discrimination Law. Bruselas, Reino Unido: Comisión Europea. Disponible en: https:// op.europa.eu/en/publication-detail/-/publication/d73a9221-b7c3-40f6-84148a48a2157a2f (Consulta: 23 agosto 2021). 
Heymann, J., Sprague, A. y Raub, A. (2020)

Advancing Equality: How Constitutional Rights Can Make a Difference Worldwide. Oakland: University of California Press. Disponible en: https://www.luminosoa.org/site/books/m/10.1525/luminos.81/(Consulta: 23 agosto 2021).

\section{ILGA World (2019)}

Homofobia de Estado: Actualización del panorama global de la legislación. Disponible en: https://ilga.org/downloads/ILGA_World_Homofobia_de_Estado_Actualizacion_Panorama_global_Legislacion_diciembre_2019.pdf (Consulta: 23 agosto 2021).

Mahlangu and Another v. Minister of Labour and Others (2020) Corte Constitucional de Sudáfrica. CCT306/19, ZACC 24. Disponible en: http:// www.saflii.org/za/cases/ZACC/2020/24.html (Consulta: 23 agosto 2021).

Majumdar, S. y Villa, V. (2020)

In 2018, Government Restrictions on Religion Reach Highest Level Globally in More than a Decade. Disponible en: https://www.pewforum.org/wp-content/ uploads/sites/7/2020/11/PF_11.10.20_religious.restrictions.full_.report.pdf (Consulta: 23 agosto 2021).

Moeller, J., et al. (2015)

'Assessing the Relationship between Dental Appearance and the Potential for Discrimination in Ontario, Canada, SSM-Population Health, 1: 26-31. Disponible en: https://doi.org/10.1016/j.ssmph.2015.11.001 (Consulta: 23 agosto 2021).

National Coalition for Gay and Lesbian Equality and Others v. Minister of Home Affairs and Others (1999)

Corte Constitucional de Sudáfrica. ZACC 17. Disponible en: http://www.saflii. org/za/cases/ZACC/1999/17.html (Consulta: 23 agosto 2021).

Nussbaum, M. (2001)

'India: Implementing Sex Equality through Law', Chicago Journal of International Law, 2(1):35-58. Disponible en: https://chicagounbound.uchicago.edu/ cjil/vol2/iss1/4/ (Consulta: 23 agosto 2021).

\section{Organización Internacional del Trabajo (2018)}

Informe Mundial sobre Salarios 2018/19: Qué hay detrás de la brecha salarial de género. Disponible en: https://www.ilo.org/wcmsp5/groups/public/---dgreports/---dcomm/---publ/documents/publication/wcms_712957.pdf (Consulta: 23 agosto 2021). 
Organización Internacional del Trabajo (2020)

Aplicación del Convenio sobre pueblos indígenas y tribales núm. 169 de la OIT: Hacia un futuro inclusivo, sostenible y justo. Disponible en: https://www.ilo. org/wcmsp5/groups/public/---dgreports/---dcomm/---publ/documents/publication/wcms_735627.pdf(Consulta: 23 agosto 2021).

Organización Internacional para las Migraciones (2019)

Informe sobre las Migraciones en el Mundo 2020. Disponible en: https://publications.iom.int/books/informe-sobre-las-migraciones-en-el-mundo-2020 (Consulta: 23 agosto 2021).

Pacto Internacional de Derechos Civiles y Políticos (1966)

Organización de Naciones Unidas. Disponible en: https://treaties.un.org/doc/ Publication/UNTS/Volume\%20999/volume-999-I-14668-English.pdf (Consulta: 23 agosto 2021).

Pacto Internacional de Derechos, y Políticos (1966)

Organización de Naciones Unidas. Disponible en: https://treaties.un.org/ doc/Treaties/1976/01/19760103\%2009-57\%20PM/Ch_IV_03.pdf (Consulta: 23 agosto 2021).

Schur, L. y Adya, M. (2013)

'Sidelined or Mainstreamed? Political Participation and Attitudes of People with Disabilities in the United States', Social Science Quarterly, 94(3):811-839. Disponible en: https://doi.org/10.1111/j.1540-6237.2012.00885.x (Consulta: 23 agosto 2021).

Siddique, Z. (2011)

'Evidence on Caste Based Discrimination, Economía laboral, 18(1):S146-S159. Disponible en: https://doi.org/10.1016/j.labeco.2011.07.002 (Consulta: 23 agosto 2021).

Sprague, A., Raub, A. y Heymann, J. (2020)

'Providing a Foundation for Decent Work and Adequate Income during Health and Economic Crises: Constitutional Approaches in 193 Countries', International Journal of Sociology and Social Policy. Disponible en: https://doi. org/10.1108/IJSSP-07-2020-0358 (Consulta: 23 agosto 2021).

\section{UNESCO (2020)}

Informe de seguimiento de la educación en el mundo 2020: informe sobre género, Una nueva generación: 25 años de esfuerzos en favor de la igualdad de género en la educación. Disponible en: https://unesdoc.unesco.org/ ark:/48223/pf0000375470 (Consulta: 23 agosto 2021). 


\section{United Nations (2016)}

Leaving No One Behind - The Imperative of Inclusive Development: Report on the World Social Situation 2016. Disponible en: https://www.un.org/development/ desa/dspd/world-social-report/rwss2016.html (Consulta: 23 agosto 2021).

Wing, A.K. (2008)

'The South African Constitution as a role model for the United States', Harvard Blackletter Law Journal, 24:73.

\section{World Economic Forum (2019)}

\section{Global Gender Gap Report 2020.}

Disponible en: http://www3.weforum.org/docs/WEF_GGGR_2020.pdf(Consulta: 23 agosto 2021).

\section{World Health Organization (2013)}

Global and regional estimates of violence against women. Prevalence and health effects of intimate partner violence and non-partner sexual violence. Disponible en: https://www.who.int/publications/i/item/9789241564625 (Consulta: 23 agosto 2021). 